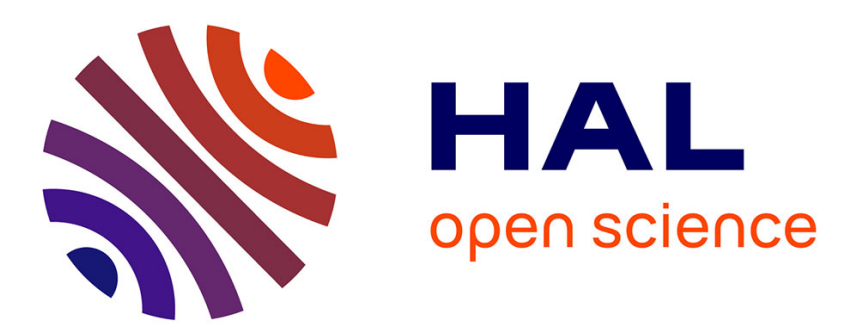

\title{
Assessment of tissue oxygenation to personalize mean arterial pressure target in patients with septic shock
}

Mathieu Jozwiak, Matthieu Chambaz, Pierre Sentenac, Xavier Monnet, Jean-Louis Teboul

\section{- To cite this version:}

Mathieu Jozwiak, Matthieu Chambaz, Pierre Sentenac, Xavier Monnet, Jean-Louis Teboul. Assessment of tissue oxygenation to personalize mean arterial pressure target in patients with septic shock. Microvascular Research, 2020, 132, pp.104068. 10.1016/j.mvr.2020.104068 . hal-02950678

\section{HAL Id: hal-02950678 \\ https://hal.science/hal-02950678}

Submitted on 30 Oct 2020

HAL is a multi-disciplinary open access archive for the deposit and dissemination of scientific research documents, whether they are published or not. The documents may come from teaching and research institutions in France or abroad, or from public or private research centers.
L'archive ouverte pluridisciplinaire HAL, est destinée au dépôt et à la diffusion de documents scientifiques de niveau recherche, publiés ou non, émanant des établissements d'enseignement et de recherche français ou étrangers, des laboratoires publics ou privés. 


\title{
Assessment of tissue oxygenation to personalize mean arterial pressure target in patients with septic shock
}

\author{
Mathieu Jozwiak $^{\mathrm{a}, \mathrm{b}, *}$, Matthieu Chambaz ${ }^{\mathrm{a}, \mathrm{b}}$, Pierre Sentenac ${ }^{\mathrm{a}, \mathrm{b}}$, Xavier Monnet ${ }^{\mathrm{a}, \mathrm{b}}$, \\ Jean-Louis Teboul ${ }^{\mathrm{a}, \mathrm{b}}$ \\ ${ }^{a}$ Hôpitaux universitaires Paris-Saclay, Hôpital de Bicêtre, assistance publique-hôpitaux de Paris, service de médecine intensive-réanimation, 78, rue du Général Leclerc, Le \\ Kremlin-Bicêtre F-94270, France \\ b Inserm UMR S 999, Univ Paris-Sud, 78, rue du Général Leclerc, Le Kremlin-Bicêtre F-94270, France
}

Keywords:

Intensive care unit

Near-infrared spectroscopy

Recovery slope

Tissue oxygenation

\begin{abstract}
A B S T R A C T
Objective: To investigate whether assessment of tissue oxygenation could help personalizing the mean arterial pressure (MAP) target in patients with septic shock.

Methods: We prospectively measured near-infrared spectroscopy variables in 22 patients with septic shock receiving norepinephrine with a MAP $>75 \mathrm{mmHg}$ within the first six hours of intensive care unit (ICU) stay for patients with community-acquired septic shock and within the first six hours of resuscitation for patients with ICU-acquired septic shock. All measurements were performed at MAP > 75 mmHg ("high-MAP") and at MAP 65-70 mmHg ("low-MAP") after decreasing the norepinephrine dose. Relative changes in StO ${ }_{2}$ recovery slope (RS) $>8 \%$ were considered clinically relevant.

Results: After decreasing the norepinephrine dose by $45 \pm 24 \%$, MAP significantly decreased from 81 [78;84] to $68[67 ; 69] \mathrm{mmHg}$, whereas cardiac index did not change. On average, the $\mathrm{StO}_{2}$-RS significantly decreased between high and low-MAP from 2.86[1.87;4.32] to 2.41 [1.14;3.72]\%/sec with a large interindividual variability: the $\mathrm{StO}_{2}$-RS decreased by $>8 \%$ in 14 patients, increased by $>8 \%$ in 4 patients and changes were $<8 \%$ in 4 patients. These changes in $\mathrm{StO}_{2}$-RS were correlated with the $\mathrm{StO}_{2}$-RS at low-MAP $(r=0.57, p=0.006)$. At highMAP, there was no difference between patients exhibiting a relevant decrease or increase in $\mathrm{StO}_{2}-\mathrm{RS}_{\text {. }}$

Conclusions: A unique MAP target may not be suitable for all patients with septic shock as its impact on peripheral oxygenation may widely differ among patients. It could make sense to personalize MAP target through a multimodal assessment including peripheral oxygenation.
\end{abstract}

\section{Introduction}

Septic shock is one of the main causes of admission in critically ill patients and its mortality remains high (Rhodes et al., 2016). In addition to macrocirculatory abnormalities, septic shock is also characterized by microcirculatory abnormalities (De Backer et al., 2002; Ince, 2005; Vincent and De Backer, 2005; Trzeciak et al., 2008), which contribute to tissue hypoxia and are also closely linked to outcome (De Backer et al., 2013).

The mean arterial pressure (MAP) is the upstream pressure for the perfusion of most vital organs. The Surviving Sepsis Campaign guidelines recommend to initially target a MAP $\geq 65 \mathrm{mmHg}$ in patients with septic shock (Rhodes et al., 2016). Vasopressors are often used for this purpose, especially when the vasomotor tone is depressed. However, excessive vasoconstriction might be deleterious on the microcirculation (Dubin et al., 2009). Recently, Fiorese Coimbra et al. demonstrated that increasing MAP from 65 to 70 to $85-90 \mathrm{mmHg}$ resulted in a significant improvement in sublingual microcirculation in patients with septic shock, regardless a medical history of arterial hypertension (Fiorese Coimbra et al., 2019). This suggests that targeting a MAP $>85 \mathrm{mmHg}$ with vasopressors in patients with septic shock is on average beneficial in terms of microcirculation, although the individual behavior of microcirculation and tissue oxygenation induced by MAP changes remains unclear (Dubin et al., 2009; Thooft et al., 2011). Thus, whether

Abbreviations: MAP, mean arterial pressure; NIRS, near-infrared spectroscopy; SAPS, simplified acute physiology score; $\mathrm{StO}_{2}$, muscle tissue oxygenation; VOT, vascular occlusion test

* Corresponding author at: Service de médecine intensive et réanimation et de surveillance continue médicale, Hôpitaux universitaires Paris-Sud, Hôpital de Bicêtre, AP-HP, 78 rue du Général Leclerc, Le Kremlin-Bicêtre F-94270, France.

E-mail address: mathieu.jozwiak@aphp.fr (M. Jozwiak). 
assessment of tissue oxygenation and microcirculation could help intensivists to personalize the MAP target in such patients is still unresolved.

Peripheral oxygenation can be assessed at the bedside by using nearinfrared spectroscopy (NIRS) through the measurement of the muscle tissue oxygenation $\left(\mathrm{StO}_{2}\right)$ and the $\mathrm{StO}_{2}$ recovery slope, which reflects the capacity of microvessels to dilate and/or to be recruited in response to a local hypoxic stimulus induced by a vascular occlusion test (VOT) (Mayeur et al., 2011). In patients with septic shock, the $\mathrm{StO}_{2}$ recovery slope, unlike the $\mathrm{StO}_{2}$, was shown to be an independent prognostic factor (Creteur et al., 2007; Shapiro et al., 2011) and thus could be an interesting parameter to personalize the MAP target in patients with septic shock.

Thus, we conducted a prospective study in our unit to assess in patients with septic shock and MAP > $75 \mathrm{mmHg}$ (called "high-MAP") whether lowering MAP to $65-70 \mathrm{mmHg}$ (called "low-MAP") had an impact on the $\mathrm{StO}_{2}$ recovery slope.

\section{Material and methods}

The study was approved by the Institutional Review Board of our institution (Comité pour la Protection des Personnes Paris VII, number IDRCB A00132-55). Informed consent was given by all patients or their next of kin.

\subsection{Study population}

We included consecutive patients within the first six hours of intensive care unit (ICU) stay for patients with community-acquired septic shock and within the first six hours of resuscitation for patients with ICU-acquired septic shock for whom: 1) the MAP was $>75 \mathrm{mmHg}$ after initial resuscitation (fluid and norepinephrine), and 2) the physician in charge decided to decrease the norepinephrine dose to target 65-70 mmHg of MAP. All patients should have been already monitored with a PiCCO-2 device (Pulsion Medical Systems, Feldkirchen, Germany), mechanically ventilated in volume assist control mode and sedated. Exclusion criteria were patients $<18$ years old, patients with arterio-venous fistula contraindicating VOT, the need for therapeutic changes during the study period or in cases of withdrawal of informed consent.

\subsection{NIRS variables}

The $\mathrm{StO}_{2}$ was measured with the InSpectra Tissue oxygenation monitor, model 650 (Hutchinson Technology, Hutchinson, MN), after placing a NIRS probe with a 15-mm distance between illumination and detection optical fibers on the thenar eminence. After at least one minute of signal stabilization, $\mathrm{StO}_{2}$ values were measured continuously and stored every two seconds before and after VOT. The VOT was performed with a pneumatic cuff placed around the forearm and rapidly inflated to $220 \mathrm{mmHg}$ and kept inflated until $\mathrm{StO}_{2}$ dropped to $40 \%$ (Mayeur et al., 2011). The $\mathrm{StO}_{2}$ recovery slope and the other NIRS variables were automatically calculated offline by the InSpectra Analysis Program V4.00 (Hutchinson Technology, Hutchinson, MN), as previously described (Mayeur et al., 2011).

\subsection{Transpulmonary thermodilution measurements}

All patients had a central venous catheter inserted in the superior vena cava territory into the internal jugular vein and a thermistortipped arterial catheter placed into the femoral artery. All thermodilution measurements were performed by injecting a $15-\mathrm{mL}$ bolus of cold saline through the central venous catheter. The average result from three consecutive 15-mL injections was recorded for each patient (Monnet et al., 2011).

\subsection{Study design}

A first set of measurements was performed at high-MAP. The norepinephrine dose was then decreased to target low-MAP. After a 30-min stabilization period, a second set of measurements was performed.

\subsection{Statistical analysis}

Variables were summarized as median [interquartile] or counts and percentages. Comparisons were performed using a Fisher's exact test for categorical variables and using a Mann-Whitney $U$ test or a Wilcoxon test for continuous variables. Correlations were assessed by Spearman's coefficient of rank correlation. We considered as relevant a relative change in $\mathrm{StO}_{2}$ recovery slope $>8 \%$ (Mayeur et al., 2011). Statistical analysis was performed with MedCalc 11.6.0 software (MedCalc, Mariakerke, East Flanders, Belgium) and a $p$ value $<0.05$ was considered statistically significant.

\section{Results}

\subsection{Study population}

The study was prematurely stopped after the inclusion of 22 patients, as NIRS probes were no longer commercialized in Europe. Among the 22 patients (67 [57;77] years old, SAPSII 56[45;68], 50\% of men), $17(77 \%)$ had history of chronic hypertension and/or diabetes mellitus. The ICU mortality was $27 \%$. Pneumonia was the source of infection in $77 \%$ of patients and $14 \%$ of patients had ICU-acquired septic shock. The other baseline characteristics of patients are summarized in Table 1 . To achieve low-MAP, the norepinephrine dose $(0.68[0.45 ; 1.22] \mu \mathrm{g} / \mathrm{kg} / \mathrm{min})$ was decreased by $45 \pm 24 \%$. MAP significantly decreased from $81[78 ; 84]$ to $68[67 ; 69] \mathrm{mmHg}$ whereas the cardiac index remained unchanged (Table 2).

\subsection{Effects of MAP changes on $\mathrm{StO}_{2}$ recovery slope}

In the whole population, the $\mathrm{StO}_{2}$ recovery slope significantly decreased between high and low-MAP from 2.86 [1.87;4.32] to $2.41[1.14 ; 3.72] \% / \sec (p=0.02)$ (Table 2 , Fig. $1 \mathrm{~A})$. The $\mathrm{StO}_{2}$ recovery slope decreased by $>8 \%$ in 14 patients, increased by $>8 \%$ in 4 patients and changes were $<8 \%$ in 4 patients (Fig. 1B). The percent changes in $\mathrm{StO}_{2}$ recovery slope were correlated with the $\mathrm{StO}_{2}$ recovery slope at low-MAP $(r=0.57, p=0.006)$ (Fig. 2) but not with changes in MAP $(r=0.36, p=0.10)$ or in cardiac index $(r=0.38, p=0.08)$. The $\mathrm{StO}_{2}$ recovery slope at low-MAP was lower in patients exhibiting a $>8 \%$ decrease than in patients exhibiting a $>8 \%$ increase in $\mathrm{StO}_{2}$

Table 1

Patients' characteristics at baseline.

\begin{tabular}{lrl}
\hline Variables & \multicolumn{2}{c}{ Value } \\
\hline Age (years) & 67 & {$[57 ; 77]$} \\
Male (n,\%) & 11 & $(50 \%)$ \\
SAPS II & 56 & {$[45 ; 68]$} \\
SOFA score & 12 & {$[8 ; 13]$} \\
Body mass index $\left(\mathrm{kg} / \mathrm{m}^{2}\right)$ & 26 & {$[21 ; 29]$} \\
Hypertension (n,\%) & 17 & $(77 \%)$ \\
Diabetes mellitus (n,\%) & 9 & $(41 \%)$ \\
Obliterant arteriopathy (n,\%) & 4 & $(18 \%)$ \\
Use of corticosteroids (n,\%) & 5 & $(23 \%)$ \\
Fraction of inspired oxygen (\%) & 50 & {$[40 ; 70]$} \\
C-Reactiv-Protein (mg/L) & 211 & {$[102 ; 297]$} \\
Hemoglobin (g/dL) & 10.5 & {$[9.2 ; 11.5]$} \\
\hline
\end{tabular}

$\mathrm{n}=22$.

Data are expressed as median [interquartile] or counts (percentages). SAPS: Simplified Acute Physiology Score; SOFA: Sepsis-related Organ Failure Assessment. 
Table 2

Macrocirculatory, NIRS and metabolic variables of patients at high and low mean arterial pressure target.

\begin{tabular}{|c|c|c|c|c|}
\hline \multirow[t]{2}{*}{ Variables } & \multicolumn{4}{|c|}{ Value } \\
\hline & \multicolumn{2}{|c|}{ High-MAP } & \multicolumn{2}{|r|}{ Low-MAP } \\
\hline Macrocirculatory variables & & & & \\
\hline $\begin{array}{l}\text { Dose of norepinephrine } \\
\quad(\mu \mathrm{g} / \mathrm{kg} / \mathrm{min})\end{array}$ & 0.68 & {$[0.45 ; 1.22]$} & 0.36 & {$[0.27 ; 0.60]^{*}$} \\
\hline MAP (mmHg) & 81 & {$[78 ; 84]$} & 68 & {$[67 ; 69]^{*}$} \\
\hline Heart rate (beats/min) & 89 & {$[78 ; 104]$} & 87 & {$[79 ; 102]$} \\
\hline Cardiac index $\left(\mathrm{L} / \mathrm{min} / \mathrm{m}^{2}\right)$ & 3.22 & {$[2.40 ; 4.10]$} & 3.12 & {$[2.28 ; 3.93]$} \\
\hline SVRI (dynes.sec $/ \mathrm{cm}^{5} / \mathrm{m}^{2}$ ) & 1916 & {$[1579 ; 2604]$} & 1786 & {$[1444 ; 2256]^{*}$} \\
\hline \multicolumn{5}{|l|}{ NIRS variables } \\
\hline $\mathrm{StO}_{2}(\%)$ & 80 & {$[77 ; 89]$} & 79 & {$[75 ; 90]$} \\
\hline Peak of $\mathrm{StO}_{2}(\%)$ & 91 & {$[90 ; 96]$} & 90 & {$[86 ; 95]$} \\
\hline Occlusion slope $(\% / \mathrm{min})$ & -8.76 & {$[-10.86 ;-7.26]$} & -9.00 & {$[-10.79 ;-7.96]$} \\
\hline Recovery slope $(\% / \mathrm{sec})$ & 2.86 & {$[1.87 ; 4.32]$} & 2.41 & {$[1.14 ; 3.72]^{*}$} \\
\hline $\begin{array}{l}\text { Hyperemia recovery area } \\
\text { (arbitrary units) }\end{array}$ & 13.12 & {$[9.65 ; 25.09]$} & 11.65 & {$[7.49 ; 19.13]$} \\
\hline \multicolumn{5}{|l|}{ Metabolic variables } \\
\hline Temperature $\left({ }^{\circ} \mathrm{C}\right)$ & 36.8 & {$[35.7 ; 37.4]$} & 36.9 & {$[36.0 ; 37.5]$} \\
\hline $\mathrm{SpO}_{2}(\%)$ & 99 & {$[96 ; 100]$} & 99 & {$[96 ; 100]$} \\
\hline $\mathrm{PaO}_{2} / \mathrm{FiO}_{2}$ ratio & 211 & {$[155 ; 280]$} & 242 & {$[160 ; 289]$} \\
\hline Lactate $(\mathrm{mmol} / \mathrm{L})$ & 1.7 & {$[1.1 ; 2.8]$} & 1.7 & {$[1.2 ; 2.5]$} \\
\hline Hemoglobin $(\mathrm{g} / \mathrm{dL})$ & 10.6 & {$[9.3 ; 11.9]$} & 10.3 & {$[9.1 ; 11.1]$} \\
\hline
\end{tabular}

$\mathrm{n}=22$. Data are expressed as median [interquartile].

MAP: mean arterial pressure; SVRI: indexed systemic vascular resistance; NIRS: near-infrared spectroscopy;

$\mathrm{StO}_{2}$ : muscle tissue oxygen saturation; $\mathrm{SpO}_{2}$ : pulsed oxygen saturation; $\mathrm{PaO}_{2}$ : partial pressure of arterial oxygen; $\mathrm{FiO}_{2}$ : fraction of inspired oxygen.

${ }^{*} p<0.05$, low $v s$. high-MAP.

recovery slope $(1.97[1.10 ; 2.58]$ vs. $3.73[3.68 ; 4.50] \% / \mathrm{sec}$, respectively, $p=0.004)$.

At high-MAP, there was no difference in demographic, macrocirculatory, NIRS and metabolic variables between patients exhibiting a $>8 \%$ decrease or a $>8 \%$ increase in $\mathrm{StO}_{2}$ recovery slope between high and low-MAP (Table 3). Changes in $\mathrm{StO}_{2}$ recovery slope were not different between patients with and without history of chronic hypertension or diabetes mellitus.

A

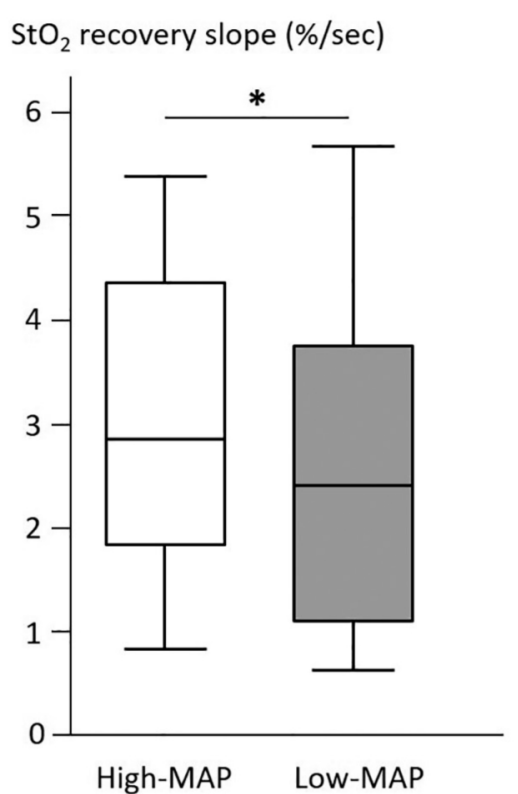

B

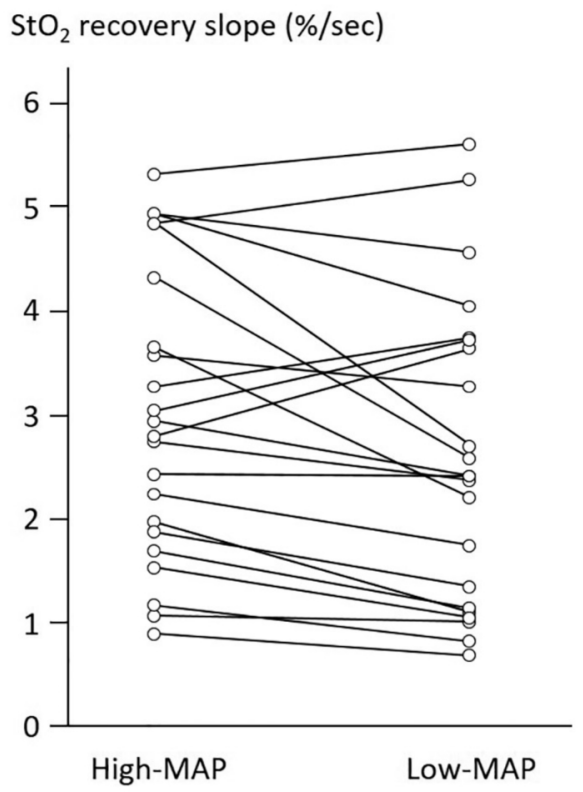

\subsection{Effects of MAP changes on the other NIRS parameters}

In the whole population, the $\mathrm{StO}_{2}$ was unchanged between high and low-MAP (80[77;89] vs. 79[75;90]\%, $p=0.48$ ) (Table 2). The $\mathrm{StO}_{2}$ was not different between high and low-MAP in patients with $>8 \%$ decrease $(79[77 ; 83]$ vs. $78[75 ; 83] \%$, respectively, $p=0.45)$ or $>8 \%$ increase $(87[78 ; 91]$ vs. $85[78 ; 92] \%$, respectively, $p=0.88)$ in $\mathrm{StO}_{2}$ recovery slope.

In the whole population, the $\mathrm{StO}_{2}$ occlusion slope $(-8.76[-10.86$; 7.26] vs. $-9.00[-10.79 ;-7.96] \% / \mathrm{min}, p=0.73$ ) and the hyperemia recovery area were unchanged between high and low-MAP (Table 2). The $\mathrm{StO}_{2}$ occlusion slope decreased in 12 patients and increased in 10 patients.

\section{Discussion}

The individual behavior of microcirculation and tissue oxygenation induced by MAP changes in patients with septic shock is still matter of debate. Here, we aimed at presenting the individual changes of $\mathrm{StO}_{2}$ recovery slope following MAP decrease in patients after the resuscitation phase of septic shock. We found that decreasing MAP from high to low target by decreasing the norepinephrine dose induced a decrease in $\mathrm{StO}_{2}$ recovery slope without changes in hyperemia recovery area between high and low MAP. As the latter finding suggests endothelial function did not changes in changes with MAP, the observed changes in $\mathrm{StO}_{2}$ recovery slope likely depended on changes in tissue perfusion pressure (Mesquida et al., 2012) with a better thenar muscle perfusion pressure at high MAP than at low MAP. However, we evidenced a large interindividual variability in changes in $\mathrm{StO}_{2}$ recovery slope following MAP decrease. Moreover, these changes in $\mathrm{StO}_{2}$ recovery slope were not correlated with changes in macrocirculatory variables, illustrating a possible loss of hemodynamic coherence (Ince, 2015). Finally, although the $\mathrm{StO}_{2}$ occlusion slope remained unchanged between high-MAP and low MAP, we evidenced as for the $\mathrm{StO}_{2}$ recovery slope, a large interindividual variability in changes in $\mathrm{StO}_{2}$ occlusion slope following MAP decrease. This suggests that the ability of the thenar eminence muscles to use the oxygen delivered for a given MAP target may differ from patient to patient.

Previous studies suggested that targeting a MAP at $85-90 \mathrm{mmHg}$ in patients with septic shock is on average beneficial in terms of
Fig. 1. Panel A: Muscle tissue oxygen saturation $\left(\mathrm{StO}_{2}\right)$ recovery slope at high and low mean arterial pressure (MAP) target. Open box: high-MAP and black box: low-MAP. The box show the 25th and 75th percentiles, the line in the box the median and the whiskers the minimum and maximum values, $n=22 .{ }^{*} p<0.05$ low $v s$. high-MAP.

Panel B: Individual changes in muscle tissue oxygen saturation $\left(\mathrm{StO}_{2}\right)$ recovery slope between high and low mean arterial pressure (MAP) target, $n=22$. 


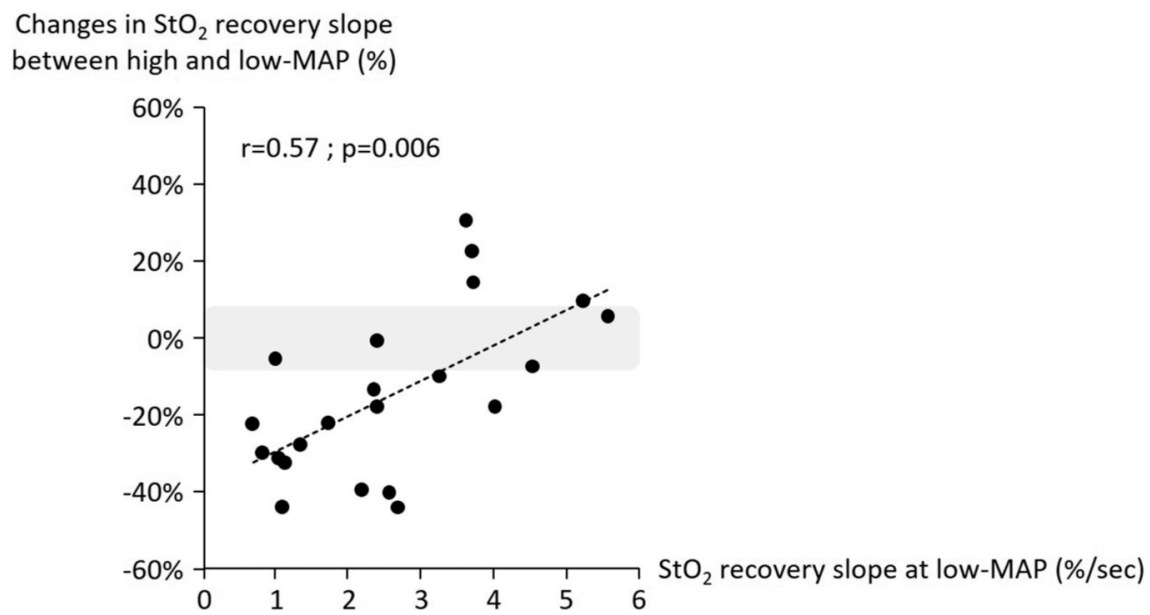

Fig. 2. Relative changes (in \%) in muscle tissue oxygen saturation $\left(\mathrm{StO}_{2}\right)$ recovery slope between high and low mean arterial pressure (MAP) target (y-axis) according to the $\mathrm{StO}_{2}$ recovery slope at low-MAP (x-axis). The grey zone represents the non-relevant $(<8 \%)$ changes in $\mathrm{StO}_{2}$ recovery slope.

microcirculation (Fiorese Coimbra et al., 2019; Thooft et al., 2011). However, the effects of MAP changes on microcirculation and tissue oxygenation could differ from one patient to another. Here, we evidenced a large interindividual variability in changes in $\mathrm{StO}_{2}$ recovery slope following MAP decrease in patients with septic shock with two opposite behaviors: the $\mathrm{StO}_{2}$ recovery slope seems to be greater at the high MAP level in the majority of patients but greater at the low MAP level in a smaller group of patients. Such an interindividual variability in the $\mathrm{StO}_{2}$ recovery slope changes could firstly depend on the state of the microcirculation. Dubin et al. showed that increasing MAP in patients with septic shock improved sublingual microcirculation only in patients with impaired microcirculation at baseline (Dubin et al., 2009). Similarly, we found that changes in $\mathrm{StO}_{2}$ recovery slope between high and low-MAP were correlated with the $\mathrm{StO}_{2}$ recovery slope at lowMAP. Furthermore, 93\% of patients exhibiting a $>8 \%$ decrease in $\mathrm{StO}_{2}$ recovery slope between high and low-MAP had abnormally low

Table 3

Demographic, macrocirculatory, NIRS and metabolic variables at high mean arterial pressure target in patients with relevant changes in $\mathrm{StO}_{2}$ recovery slope between high and low mean arterial pressure target.

\begin{tabular}{|c|c|c|c|c|}
\hline \multirow[t]{2}{*}{ Variables } & \multicolumn{4}{|c|}{ Value } \\
\hline & Decrease in $\mathrm{StO}_{2}$ recovery & $\begin{array}{l}\text { slope from high to low-MAP }>8 \% \\
(\mathrm{n}=14)\end{array}$ & Increase in $\mathrm{StO}_{2}$ recover & $\begin{array}{l}\text { slope from high to low-MAP }>8 \% \\
(n=4)\end{array}$ \\
\hline \multicolumn{5}{|l|}{ Demographic variables } \\
\hline Age (years) & 70 & {$[56 ; 79]$} & 69 & {$[58 ; 80]$} \\
\hline Male $(n, \%)$ & 8 & $(57 \%)$ & 2 & $(50 \%)$ \\
\hline SAPS II & 55 & {$[45 ; 68]$} & 57 & {$[46 ; 64]$} \\
\hline SOFA score & 13 & {$[8 ; 14]$} & 10 & {$[8 ; 12]$} \\
\hline Body mass index $\left(\mathrm{kg} / \mathrm{m}^{2}\right)$ & 26 & {$[21 ; 29]$} & 28 & {$[23 ; 33]$} \\
\hline Hypertension $(\mathrm{n}, \%)$ & 12 & $(86 \%)$ & 3 & $(75 \%)$ \\
\hline Diabetes mellitus (n,\%) & 8 & $(57 \%)$ & 1 & $(25 \%)$ \\
\hline Obliterant arteriopathy $(\mathrm{n}, \%)$ & 3 & $(21 \%)$ & 1 & $(25 \%)$ \\
\hline Use of corticosteroids (n,\%) & 3 & $(21 \%)$ & 1 & $(25 \%)$ \\
\hline \multicolumn{5}{|l|}{ Macrocirculatory variables at high MAP } \\
\hline Doses of norepinephrine $(\mu \mathrm{g} / \mathrm{kg} / \mathrm{min})$ & 0.73 & {$[0.48 ; 1.44]$} & 0.84 & {$[0.26 ; 1.40]$} \\
\hline MAP (mmHg) & 81 & {$[80 ; 83]$} & 78 & {$[77 ; 82]$} \\
\hline Heart rate (beats/min) & 88 & {$[71 ; 101]$} & 98 & {$[81 ; 113]$} \\
\hline Cardiac index $\left(\mathrm{L} / \mathrm{min} / \mathrm{m}^{2}\right)$ & 3.64 & {$[2.40 ; 4.59]$} & 2.70 & {$[2.19 ; 3.38]$} \\
\hline SVRI (dyne.sec $/ \mathrm{cm}^{5} / \mathrm{m}^{2}$ ) & 1793 & {$[1392 ; 2595]$} & 2024 & {$[1699 ; 2544]$} \\
\hline \multicolumn{5}{|l|}{ NIRS variables at high MAP } \\
\hline $\mathrm{StO}_{2}(\%)$ & 80 & {$[77 ; 83]$} & 88 & {$[78 ; 91]$} \\
\hline Peak of $\mathrm{StO}_{2}(\%)$ & 91 & {$[89 ; 94]$} & 93 & {$[86 ; 97]$} \\
\hline Occlusion slope $(\% / \mathrm{min})$ & -8.77 & {$[-10.86 ;-7.60]$} & -8.17 & {$[-9.99 ;-5.54]$} \\
\hline Recovery slope $(\% / \mathrm{sec})$ & 2.49 & {$[1.69 ; 3.65]$} & 3.15 & {$[2.91 ; 4.05]$} \\
\hline Hyperemia recovery area (arbitrary units) $\mathrm{x}$ min) & 15.33 & {$[10.60 ; 25.27]$} & 10.29 & {$[7.66 ; 13.89]$} \\
\hline \multicolumn{5}{|l|}{ Metabolic variables at high MAP } \\
\hline Temperature $\left({ }^{\circ} \mathrm{C}\right)$ & 37.1 & {$[35.9 ; 37.6]$} & 35.7 & {$[35.4 ; 36.5]$} \\
\hline $\mathrm{SpO}_{2}(\%)$ & 98 & {$[96 ; 100]$} & 99 & {$[98 ; 100]$} \\
\hline $\mathrm{PaO}_{2} / \mathrm{FiO}_{2}$ ratio & 174 & {$[111 ; 242]$} & 198 & {$[160 ; 304]$} \\
\hline Lactate $(\mathrm{mmol} / \mathrm{L})$ & 1.7 & {$[1.2 ; 3.0]$} & 2.5 & {$[0.9 ; 4.0]$} \\
\hline Hemoglobin $(\mathrm{g} / \mathrm{dL})$ & 10.2 & {$[9.2 ; 11.6]$} & 11.0 & {$[9.3 ; 11.5]$} \\
\hline
\end{tabular}

$n=18$. Data are expressed as median [interquartile] or counts (percentages).

MAP: mean arterial pressure; SAPS: Simplified Acute Physiology Score; SOFA: Sepsis-related Organ Failure Assessment; SVRI: indexed systemic vascular resistance; NIRS: near-infrared spectroscopy; $\mathrm{StO}_{2}$ : muscle tissue oxygen saturation; $\mathrm{SpO}_{2}$ : pulsed oxygen saturation; $\mathrm{PaO}_{2}$ : partial pressure of arterial oxygen; FiO ${ }_{2}$ : fraction of inspired oxygen. 
$\mathrm{StO}_{2}$ recovery slope at low-MAP. Secondly, this interindividual variability could be explained by the potential opposite effects of the norepinephrine dose on microvascular blood flow (Legrand et al., 2019). Decreasing the norepinephrine dose might decrease the microvascular blood flow in pressure-dependent vascular beds but might also decrease the excessive local vasoconstriction and thus improve the microvascular blood flow.

Changes in $\mathrm{StO}_{2}$ recovery slope following MAP decrease appeared unpredictable. There was no difference in demographic, macrocirculatory and metabolic variables measured at high-MAP in patients exhibiting a $>8 \%$ decrease or a $>8 \%$ increase in $\mathrm{StO}_{2}$ recovery slope. Interestingly, patients had similar high $\mathrm{StO}_{2}$ values at high and low-MAP, regardless the $\mathrm{StO}_{2}$ recovery slope changes. The $\mathrm{StO}_{2}$ is a measure of the saturation of oxygen hemoglobin in microvessels (Ward et al., 2006) and is mainly driven by the $\mathrm{O}_{2}$ saturation of the venular blood (Moens et al., 2005). Such high $\mathrm{StO}_{2}$ values, previously reported in patients with septic shock (Pareznik et al., 2006; Skarda et al., 2007; Leone et al., 2009), even in severely hypotensive patients (Georger et al., 2010), can be explained by the presence of arterio-venous shunting, which result in increased $\mathrm{O}_{2}$ saturation of the venous blood. In this regard, others previously demonstrated that the $\mathrm{StO}_{2}$, unlike the $\mathrm{StO}_{2}$ recovery slope, was not an independent prognostic factor in patients with septic shock (Creteur et al., 2007; Shapiro et al., 2011), although some authors reported that persisting low $\mathrm{StO}_{2}(<70 \%)$ after a 8-h period of shock resuscitation was associated with poor outcome (Lima et al., 2009).

Finally, we found no correlation between changes in $\mathrm{StO}_{2}$ recovery slope and changes in MAP or cardiac index, highlighting the potential loss of hemodynamic coherence in patients with septic shock (Ince, 2015), as demonstrated in previous studies (De Backer et al., 2013; Fiorese Coimbra et al., 2019; Trzeciak et al., 2007).

Overall, our results suggest that a unique MAP target for every patient with septic shock is probably not suitable. It might be more valuable to personalize MAP target through a multimodal assessment that includes not only central but also peripheral markers of perfusion and/or tissue oxygenation.

We acknowledge some limitations to our study. First, we investigated one peripheral territory and we cannot exclude that the norepinephrine effects on MAP could be different in other territories, as previously illustrated (Jhanji et al., 2009). Second, the large interindividual variability in changes in $\mathrm{StO}_{2}$ recovery slope may also depend on patient-related factors other than MAP. Nevertheless, it must be noted that there was no difference in demographic, macrocirculatory and metabolic variables between patients exhibiting a decrease or increase in $\mathrm{StO}_{2}$ recovery slope. Third, due to the design of our clinical study, we studied $\mathrm{StO}_{2}$ recovery slope changes following a MAP decrease. Our results cannot prejudge the potential $\mathrm{StO}_{2}$ recovery slope changes following a MAP increase during the resuscitation phase of septic shock. Four, central venous oxygen saturation was not recorded and endothelial function was not directly investigated.

\section{Conclusions}

The conclusions of our study are twofold. First, this study only alerts us to the fact that the same MAP target is probably not suitable for all patients with septic shock. Second, it might be interesting to personalize the MAP target in patients with septic shock through a multimodal assessment that includes not only central but also peripheral markers of perfusion and/or oxygenation whatever the technique used and not necessarily with the NIRS technology.

\section{CRediT authorship contribution statement}

Mathieu Jozwiak, Xavier Monnet, Jean-Louis Teboul: Conceptualization

Matthieu Chambaz, Pierre Sentenac: Investigation
Mathieu Jozwiak, Matthieu Chambaz, Pierre Sentenac, JeanLouis Teboul: Formal analysis

Mathieu Jozwiak, Xavier Monnet, Jean-Louis Teboul: Supervision

Mathieu Jozwiak, Xavier Monnet, Jean-Louis Teboul: Validation Mathieu Jozwiak, Matthieu Chambaz, Pierre Sentenac, Xavier Monnet, Jean-Louis Teboul Writing - Original draft

Mathieu Jozwiak, Jean-Louis Teboul: Writing - review \& editing

\section{Declaration of competing interest}

The authors declare the following financial interests/personal relationships which may be considered as potential competing interests: JLT and XM are members of the medical advisory board of Pulsion Medical Systems. The other authors have no conflict of interest to declare.

\section{Acknowledgments}

None.

\section{Funding sources}

This research did not receive any specific grant from funding agencies in the public, commercial, or not-for-profit sectors.

\section{References}

Creteur, J., Carollo, T., Soldati, G., Buchele, G., De Backer, D., Vincent, J.L., 2007. The prognostic value of muscle $\mathrm{StO} 2$ in septic patients. Intensive Care Med. 33, 1549-1556.

De Backer, D., Creteur, J., Preiser, J.C., Dubois, M.J., Vincent, J.L., 2002. Microvascular blood flow is altered in patients with sepsis. Am. J. Respir. Crit. Care Med. 166, 98-104.

De Backer, D., Donadello, K., Sakr, Y., Ospina-Tascon, G., Salgado, D., Scolletta, S., Vincent, J.L., 2013. Microcirculatory alterations in patients with severe sepsis: impact of time of assessment and relationship with outcome. Crit. Care Med. 41, 791-799.

Dubin, A., Pozo, M.O., Casabella, C.A., Palizas Jr., F., Murias, G., Moseinco, M.C., Kanoore Edul, V.S., Palizas, F., Estenssoro, E., Ince, C., 2009. Increasing arterial blood pressure with norepinephrine does not improve microcirculatory blood flow: a prospective study. Crit. Care 13, R92.

Fiorese Coimbra, K.T., de Freitas, F.G.R., Bafi, A.T., Pinheiro, T.T., Nunes, N.F., de Azevedo, L.C.P., Machado, F.R., 2019. Effect of increasing blood pressure with noradrenaline on the microcirculation of patients with septic shock and previous arterial hypertension. Crit. Care Med. 47, 1033-1040.

Georger, J.F., Hamzaoui, O., Chaari, A., Maizel, J., Richard, C., Teboul, J.L., 2010. Restoring arterial pressure with norepinephrine improves muscle tissue oxygenation assessed by near-infrared spectroscopy in severely hypotensive septic patients. Intensive Care Med. 36, 1882-1889.

Ince, C., 2005. The microcirculation is the motor of sepsis. Crit. Care 9 (Suppl. 4), S13-S19.

Ince $\mathrm{C}$. Hemodynamic coherence and the rationale for monitoring the microcirculation. Crit Care 2015; 19 Suppl 3: S8.

Jhanji, S., Stirling, S., Patel, N., Hinds, C.J., Pearse, R.M., 2009. The effect of increasing doses of norepinephrine on tissue oxygenation and microvascular flow in patients with septic shock. Crit. Care Med. 37, 1961-1966.

Legrand, M., De Backer, D., Depret, F., Oufella, H.A., 2019. Recruiting the microcirculation in septic shock. Ann. Intensive Care 9, 102.

Leone, M., Blidi, S., Antonini, F., Meyssignac, B., Bordon, S., Garcin, F., Charvet, A., Blasco, V., Albanese, J., Martin, C., 2009. Oxygen tissue saturation is lower in nonsurvivors than in survivors after early resuscitation of septic shock. Anesthesiology $111,366-371$.

Lima A, van Bommel J, Jansen TC, Ince C, Bakker J. Low tissue oxygen saturation at the end of early goal-directed therapy is associated with worse outcome in critically ill patients. Crit Care 2009; 13 Suppl 5: S13.

Mayeur, C., Campard, S., Richard, C., Teboul, J.L., 2011. Comparison of four different vascular occlusion tests for assessing reactive hyperemia using near-infrared spectroscopy. Crit. Care Med. 39, 695-701.

Mesquida, J., Espinal, C., Gruartmoner, G., Masip, J., Sabatier, C., Baigorri, F., Pinsky, M.R., Artigas, A., 2012. Prognostic implications of tissue oxygen saturation in human septic shock. Intensive Care Med. 38, 592-597.

Moens, A.L., Goovaerts, I., Claeys, M.J., Vrints, C.J., 2005. Flow-mediated vasodilation: a diagnostic instrument, or an experimental tool? Chest 127, 2254-2263.

Monnet, X., Persichini, R., Ktari, M., Jozwiak, M., Richard, C., Teboul, J.L., 2011. Precision of the transpulmonary thermodilution measurements. Crit. Care 15, R204.

Pareznik, R., Knezevic, R., Voga, G., Podbregar, M., 2006. Changes in muscle tissue oxygenation during stagnant ischemia in septic patients. Intensive Care Med. 32, 
87-92.

Rhodes A, Evans LE, Alhazzani W, Levy MM, Antonelli M, Ferrer R, Kumar A, Sevransky JE, Sprung CL, Nunnally ME, Rochwerg B, Rubenfeld GD, Angus DC, Annane D, Beale RJ, Bellinghan GJ, Bernard GR, Chiche JD, Coopersmith C, De Backer DP, French CJ, Fujishima S, Gerlach H, Hidalgo JL, Hollenberg SM, Jones AE, Karnad DR, Kleinpell RM, Koh Y, Lisboa TC, Machado FR, Marini JJ, Marshall JC, Mazuski JE, McIntyre LA, McLean AS, Mehta S, Moreno RP, Myburgh J, Navalesi P, Nishida O, Osborn TM, Perner A, Plunkett CM, Ranieri M, Schorr CA, Seckel MA, Seymour CW, Shieh L, Shukri KA, Simpson SQ, Singer M, Thompson BT, Townsend SR, Van der Poll T, Vincent JL, Wiersinga WJ, Zimmerman JL, Dellinger RP. Surviving Sepsis Campaign: International Guidelines for Management of Sepsis and Septic Shock: 2016. Intensive Care Med 2017; 43:304-377.

Shapiro NI, Arnold R, Sherwin R, O'Connor J, Najarro G, Singh S, Lundy D, Nelson T, Trzeciak SW, Jones AE, Emergency Medicine Shock Research N. The association of near-infrared spectroscopy-derived tissue oxygenation measurements with sepsis syndromes, organ dysfunction and mortality in emergency department patients with sepsis. Crit. Care 2011; 15: R223.

Skarda, D.E., Mulier, K.E., Myers, D.E., Taylor, J.H., Beilman, G.J., 2007. Dynamic nearinfrared spectroscopy measurements in patients with severe sepsis. Shock 27,
348-353.

Thooft, A., Favory, R., Salgado, D.R., Taccone, F.S., Donadello, K., De Backer, D., Creteur, J., Vincent, J.L., 2011. Effects of changes in arterial pressure on organ perfusion during septic shock. Crit. Care 15, R222.

Trzeciak S, Dellinger RP, Parrillo JE, Guglielmi M, Bajaj J, Abate NL, Arnold RC, Colilla S, Zanotti S, Hollenberg SM, Microcirculatory Alterations in R, Shock I. Early microcirculatory perfusion derangements in patients with severe sepsis and septic shock: relationship to hemodynamics, oxygen transport, and survival. Ann Emerg Med 2007; 49: 88-98, 98 e81-82.

Trzeciak, S., Cinel, I., Phillip Dellinger, R., Shapiro, N.I., Arnold, R.C., Parrillo, J.E., Hollenberg, S.M., 2008. Microcirculatory alterations in R, shock I. resuscitating the microcirculation in sepsis: the central role of nitric oxide, emerging concepts for novel therapies, and challenges for clinical trials. Acad. Emerg. Med. 15, 399-413.

Vincent, J.L., De Backer, D., 2005. Microvascular dysfunction as a cause of organ dysfunction in severe sepsis. Crit. Care 9 (Suppl. 4), S9-12.

Ward, K.R., Ivatury, R.R., Barbee, R.W., Terner, J., Pittman, R., Filho, I.P., Spiess, B., 2006. Near infrared spectroscopy for evaluation of the trauma patient: a technology review. Resuscitation 68, 27-44. 